\title{
GAMBARAN PENGETAHUAN REMAJA MADYA (13 -15 TAHUN) TENTANG DYSMENORRHEA DI SMPN 29 KOTA BANDUNG
}

\author{
${ }^{1}$ Septian Andriyani, ${ }^{2}$ Sri Sumartini, ${ }^{3}$ Vevi Nur Afifah \\ ${ }^{1,2,3}$ Prodi D3 Keperawatan FPOK Universitas Pendidikan Indonesia \\ Email: srisumartini@upi.edu
}

\begin{abstract}
ABSTRAK
Dysmenorrhea umum dirasakan oleh perempuan pada hari - hari pertama menstruasi. Tidak banyak yang menyadari bahwa dysmenorrhea yang tidak biasa bisa menjadi salah satu awal dari suatu penyakit misalnya endometriosis, sehingga perlu diberikan edukasi tentang dysmenorrhea sebagai upaya deteksi dini terjadinya kasus endometriosis. Angka Kejadian dysmenorrhea di Indonesia sendiri cukup tinggi mencapai $64,25 \%$ yang terdiri dari 54,89\% dysmenorrhea primer dan 9,36\% dysmenorrhea sekunder tidak jauh berbeda dengan angka kejadian dysmenorrhea di Jawa Barat yaitu sebanyak 54,9 \% wanita mengalami dysmenorrhea, terdiri dari $24,5 \%$ mengalami dysmenorrhea ringan, $21,28 \%$ mengalami dysmenorrhea sedang dan 9,36\% mengalami dysmenorrhea berat. Penelitian ini bertujuan untuk mengetahui gambaran pengetahuan remaja madya usia 13 - 15 tahun tentang dysmenorrhea. Jumlah keseluruhan populasi dalam penelitian ini sebanyak 423 siswi yang terdiri atas siswi kelas VII sebanyak 256 orang dan siswi kelas VIII sebanyak 167orang. Penelitian ini merupakan penelitian deskriptif kuantitatif dengan melibatkan 206 sampel siswi yang diambil menggunakan teknik Proportionate Stratified Random Sampling. Hasil penelitian menunjukkan bahwa sebagian besar berada pada kategori berpengetahuan baik, dengan hasil sebanyak 115 siswi (55,8\%). Namun, masih ditemukan sebagian kecil siswi dalam kategori berpengetahuan cukup yaitu sebanyak 22 siswi $(10,7 \%)$ dan hampir setengahnya berpengetahuan kurang yaitu sebanyak 69 siswi (33,5\%). Dari hasil tersebut kategori berpengetahuan kurang masih hampir setengah jumlah responden. Oleh karena itu, diharapkan pihak sekolah dapat bekerja sama dengan Puskesmas ataupun petugas kesehatan terkait dalam pemberian pendidikan kesehatan khususnya tentang dysmenorrhea secara berkala kepada siswi SMPN 29 Kota Bandung.
\end{abstract}

Kata kunci: Dysmenorrhea, Pengetahuan, Remaja Madya,

\begin{abstract}
Dysmenorrhea is commonly experienced by women at the beginning of the menstruation period. There are only few who realize that unusual dysmenorrhea can be an initial symptom of certain diseases, such as endometriosis, so that they should be educated about dysmenorrhea as an early warning effort to detect endometriosis cases. The number of dysmenorrhea in Indonesia is relatively high, in which it achieved $64.25 \%$. It consisted of $54.89 \%$ primary dysmenorrhea and $9.36 \%$ secondary dysmenorrhea. Similar case was also found in West Java in which around $54.9 \%$ women experienced dysmenorrhea. The figure consisted of $24.5 \%$ women experienced light dysmenorrhea, $21.28 \%$ women experienced moderate dysmenorrhea, and $9.36 \%$ of them experienced severe dysmenorrhea. The current research aims to discover the understanding of 13-15 years old adolescents on dysmenorrhea. There were total 423 female students involved in this research, which consisted of 256 seventh grade female students and 167 eighth grade female students. This research was categorized as descriptive quantitative research, which involved 206 female students as the research sample that were selected by employing Proportionate Stratified Random Sampling. The research result revealed that most of the students (115 students or 55.8\%) were categorized to have good understanding on dysmenorrhea. However, it was also discovered that there were minority of the students (22 students or 10.7\%) who were considered to have adequate understanding, while almost the half of the students (69 students or 33.5\%) had limited understanding on dysmenorrhea. Based on the aforementioned result, it is found that almost half of the population still had limited understanding on the matter. Therefore, it is expected that the school administrators can cooperate with community health centers or medical practitioners in order to regularly educate the female students at SMPN 29 in Bandung mainly about dysmenorrhea.
\end{abstract}

Keywords: Adolescents, Dysmenorrhea, Knowledge 


\section{PENDAHULUAN}

Setiap manusia pasti akan mengalami masa remaja. Pada remaja putri terjadi suatu perubahan fisik yaitu perubahan organ-organ reproduksi yang ditandai dengan datangnya menstruasi (Kumalasari dan Andhyantoro, 2012). Menstruasi adalah perdarahan vagina secara berkala akibat terlepasnya lapisan endometrium uterus. Usia normal bagi seorang wanita mendapat menstruasi untuk pertama kalinya pada usia 12 atau 13 tahun dan ada pula yang mengalaminya lebih awal, yaitu pada usia 8 tahun atau lebih lambat yaitu usia 18 tahun. Menstruasi akan berhenti dengan sendirinya pada saat wanita sudah berusia 40-50 tahun, yang dikenal dengan istilah menopause (Sukarni dan Margareth, 2013).

Pada sebagian remaja yang mengalami menstruasi akan timbul nyeri saat menstruasi yang biasanya disebut dysmenorrhea. Dysmenorrhea berasal dari bahasa Yunani: dys yang berarti sulit, nyeri, abnormal, meno berarti bulan, dan rrhea berarti aliran. Dysmenorrhea atau dismenorea dalam bahasa Indonesia berarti nyeri pada saat menstruasi. Dysmenorrhea merupakan permasalahan ginekologikal utama yang paling sering dikeluhkan remaja (French, 2008), dan yang paling umum terjadi ialah dysmenorrhea primer (Zukri, 2009).

Dampak yang diakibatkan oleh dysmenorrhea berupa gangguan aktivitas seperti tingginya tingkat absen dari sekolah maupun kerja, keterbatasan kehidupan sosial, performa akademik, serta aktivitas olahraganya (Patel, 2006 ; Loto, 2008; Cakir, 2009; Zukri, 2009). Selain mengganggu aktivitas sehari-hari dan menurunnya kinerja yaitu biasanya mengalami mual, kadang disertai muntah dan diare. Masih banyak wanita yang menganggap nyeri haid sebagai hal yang biasa, mereka beranggapan 1-2 hari sakitnya akan hilang. Padahal nyeri haid hebat bisa menjadi tanda dan gejala suatu penyakit misalnya endometriosis yang bisa mangakibatkan sulitnya keturunan (Sarwono,
2008). Pada anak remaja penyebab nyeri haid dipikirkan karena hanya kadar prostaglandin yang tinggi bukan karena endrometriosis, maka biasanya pengobatan yang diberikan adalah obat penghilang rasa nyeri saja (Departemen Obstetri dan Ginekologi FK UNPAD, 2011).

Klein dan Litt melaporkan prevalensi dysmenorrhea di Amerika Serikat mencapai $59,7 \%$. Beberapa dari mereka yang mengeluh nyeri, $12 \%$ berat, $37 \%$ sedang, dan $49 \%$ ringan (Bonde 2014, dalam jurnal Keperawatan Aisyiyah, 2015). Studi yang dilakukan oleh (Cakir, 2007) pada mahasiswi di Turki menunjukan hasil yang sangat mencengangkan yaitu prevalensi kejadian dysmenorrhea sebesar $89,5 \%$ dan $10 \%$ nya mengalami tingkat berat. Penelitian yang sama pada mahasiswi di Turki mengenai dysmenorrhea primer dengan hasil yang tidak jauh berbeda yaitu sebesar $88 \%$ dan sebanyak 45,3\% mengalami dysmenorrhea disetiap periode menstruasi (Polat, 2009). Studi di Yordania pada remaja putri juga menunjukkan hal serupa yaitu sebanyak $87,4 \%$ mengalami dysmenorrhea primer dan sebanyak $46 \%$ mengalami dysmenorrhea tingkat berat (Razzak, 2010). Daerah Asia sendiri, prevalensi dysmenorrhea primer juga cukup tinggi yaitu di taiwan menunjukan prevalensi sebesar 75,2\% (Yu dan Yueh, 2009), yang tak jauh dengan prevalensi pada mahasiswi di Malaysia yaitu sebesar 50,9\%,. Angka Kejadian dysmenorrhea di Indonesia sendiri mencapai $64,25 \%$ yang terdiri dari $54,89 \%$ dysmenorrhea primer dan 9,36\% dysmenorrhea sekunder. Wilayah Surabaya di dapatkan 1,07\% menderita dysmenorrhea dan $1,31 \%$ dari jumlah penderita dysmenorrhea datang kebagian kebidanan (Ernawati, 2010).

Hasil penelitian Pusat Informasi dan Konseling Kesehatan Reproduksi Remaja (PIK-KRR) di Indonesia tahun 2009 angka kejadian dysmenorrhea berkisar 45 - 95\% dikalangan usia produktif, terdiri dari $72,84 \%$ dysmenorrhea primer dan $27,11 \%$ 
dysmenorrhea sekunder (Proverawati \& Maisaroh, 2009). Berdasarkan data hasil penelitian angka kejadian dysmenorrhea di Jawa Barat cukup tinggi, yaitu sebanyak 54,9 $\%$ wanita mengalami dysmenorrhea, terdiri dari $24,5 \%$ mengalami dysmenorrhea ringan, 21,28\% mengalami dysmenorrhea sedang dan 9,36\% mengalami dysmenorrhea berat (Arnis 2012, dalam jurnal keperawatan Aisyiyah, 2015). Data dari PKPR dan Puskesmas menunjukkan bahwa gangguan haid di Bandung menduduki peringkat tertinggi, yaitu $73 \%$ data dari puskesmas dan $82 \%$ data dari PKPR disusul oleh masalah Penyakit Menular Seksual sebanyak $8 \%$ dan konsultasi KB 4 \%. (LPPM UPI, 2011). Selain itu, berdasarkan data hasil dari Puskesmas Ledeng sepanjang tahun 2015 Puskesmas tersebut menerima 95 pasien remaja putri dengan keluhan dysmenorrhea.

Penelitian sebelumnya yang dilakukan oleh Releghea A.Y. (2012) tentang hubungan antara pengetahuan dysmenorrhea dengan perilaku penanganan mengatasinya di SMAN Mojoangung, didapatkan hasil yang menunjukan bahwa dari 133 responden sebanyak 44\% memiliki pengetahuan cukup. Penelitian serupa juga dilakukan oleh Sri Mulyani (2012) yang meneliti tingkat pengetahuan remaja putri tentang dysmenorrhea di SMPN 1 Kedawung Sragen terhadap 30 responden didapatkan hasil 5 siswi $(16,67 \%)$ berpengetahuan baik, 21 siswi (70\%) cukup dan berpengetahuan buruk 4 siswi $(13,33 \%)$.

SMPN 29 Kota Bandung terpilih sebagai lokasi penelitian, karena sekolah ini merupakan salah satu sekolah dengan jumlah siswi terbilang banyak. Dari total 67.288 jumlah siswi SMP di Kota Bandung (LPPM UPI, 2011), sebanyak 647 siswi bersekolah di SMPN 29 Bandung, akan tetapi pada penelitian ini peneliti mengambil siswi kelas VII dan VIII sejumlah 423 siswi sebagai partisipan penelitian, Karena rata - rata mereka sudah berusia 13 - 15 tahun dimana usia tersebut merupakan usia yang memasuki tahap Remaja Madya (Middle Adolescence) dan merupakan usia dimana rata - rata remaja putri sudah mengalami menstruasi.

Hasil studi pendahuluan yang dilakukan pada tanggal 9 Maret 2016, dengan teknik wawancara kepada 15 orang remaja putri di SMPN 29 Kota Bandung yang telah mengalami menstruasi mengenai Pengetahuan mereka tentang dysmenorrhea didapatkan hasil, 10 orang mengatakan selalu mengalami nyeri saat menstruasi dengan intensitas nyeri dari ringan hingga sedang, tetapi masih belum tahu penyebab timbulnya nyeri saat haid dan belum tahu penanganan yang tepat saat sakit haid, tiga orang tidak pernah merasakan sakit saat haid, dua orang jarang mengalami nyeri haid dan hanya cukup dengan beristirahat saat nyeri timbul.

Ini menunjukan bahwa pengetahuan mereka tentang dysmenorrhea masih belum optimal, oleh karena itu diperlukan komunikasi dan informasi bagi masyarakat khususnya remaja putri tentang dysmenorrhea

Berdasarkan uraian latar belakang diatas, peneliti tertarik untuk meneliti mengenai "Gambaran Pengetahuan Remaja Madya (13 - 15 Tahun) Tentang Dysmenorrhea di SMPN 29 Kota Bandung”.

\section{METODE}

Penelitian ini merupakan penelitian deskriptif dengan pendekatan kuantitatif . Rancangan penelitian menggunakan teknik Proportionate Stratified Random Sampling. Penelitian ini dilakukan pada tanggal $24 \mathrm{Mei}$ 2016 dengan jumlah responden 206 orang. Instrumen yang digunakan dalam penelitian ini dibuat dalam bentuk butir soal sebanyak 23 item.

\section{HASIL}

\section{Karakteristik Responden}

Pada penelitian ini data demografi responden hanya mencakup usia saja. Secara rinci dapat dilihat sebagai berikut : 
Tabel 1. Distribusi Frekuensi Data Demografi Responden

\begin{tabular}{lcc}
\hline Kategori & F & $\mathbf{( \% )}$ \\
\hline 13 Tahun & 120 & 58,3 \\
14 Tahun & 84 & 40,8 \\
15 Tahun & 2 & 0,97 \\
\hline Total & $\mathbf{2 0 6}$ & $\mathbf{1 0 0}$ \\
\hline
\end{tabular}

Gambaran Pengetahuan Remaja Madya (13 - 15 tahun) tentang Dysmenorrhea di SMPN 29 Kota Bandung

Hasil yang didapat setelah setelah melakukan pengisian butir soal mengenai pengetahuan remaja madya (13-15 tahun) tentang dysmenorrhea di SMPN 29 Kota Bandung adalah sebagai berikut :

Tabel 2. Distribusi Frekuensi Pengetahuan Remaja Madya (13-15 tahun) Tentang Dysmenorrhea di SMPN 29 Kota Bandung

\begin{tabular}{lcc}
\hline Kategori & F & $\mathbf{( \% )}$ \\
\hline Baik & 115 & 55,8 \\
Cukup & 22 & 10,7 \\
Kurang & 69 & 33,5 \\
\hline \multicolumn{1}{c}{ Total } & $\mathbf{2 0 6}$ & $\mathbf{1 0 0}$ \\
\hline
\end{tabular}

Berdasarkan tabel 2, dapat dilihat bahwa siswa kelas VII dan VIII SMPN 29 Kota Bandung berada pada kategori berpengetahuan baik sebanyak 115 orang (55,8\%), berpengetahuan cukup sebanyak 22 orang $(10,7 \%)$ dan berpengetahuan kurang sebanyak 69 orang $(33,5 \%)$. Adapun rincian gambaran pengetahuan berdasarkan distribusi frekuensi indikator pengetahuan remaja tentang dysmenorrhea disajikan dalam tabel 3 berikut :

Tabel 3. Distribusi Frekuensi Responden Berdasarkan Indikator

\begin{tabular}{llcc}
\hline & Kategori & F & $\mathbf{( \% )}$ \\
\hline 1. & Pengertian & & \\
\hline & Baik & 50 & 103 \\
& Cukup & 61 & 31,1 \\
& Kurang & 39 & 18,9 \\
\hline 2. & Jenis & F & $\mathbf{( \% )}$ \\
\hline & Baik & 123 & 59,7 \\
& Cukup & 32 & 15,5 \\
& Kurang & 51 & 24,8 \\
\hline 3. & Penyebab & F & $\mathbf{( \% )}$ \\
\hline
\end{tabular}

\begin{tabular}{llcc}
\hline & Baik & $\mathbf{3 0}$ & $\mathbf{1 4 , 6}$ \\
& Cukup & $\mathbf{6 0}$ & $\mathbf{2 9 , 1}$ \\
& Kurang & $\mathbf{1 1 6}$ & $\mathbf{5 6 , 3}$ \\
\hline 4. & Faktor Resiko & $\mathbf{F}$ & $\mathbf{( \% )}$ \\
\hline & Baik & 143 & 69,4 \\
& Cukup & 32 & 15,5 \\
& Kurang & 31 & 15 \\
\hline $\mathbf{5 .}$ & Derajat Nyeri & $\mathbf{F}$ & $\mathbf{( \% )}$ \\
\hline & Baik & 104 & 50,5 \\
& Cukup & 40 & 19,4 \\
& Kurang & 62 & 30,1 \\
\hline 6. & Tata Laksana & F & $\mathbf{( \% )}$ \\
\hline & Baik & 134 & 65 \\
& Cukup & 31 & 15 \\
& Kurang & 41 & 19,9 \\
\hline
\end{tabular}

Berdasarkan tabel 3, dapat dilihat bahwa pengetahuan siswi tentang pengertian dismenorea menunjukan pengetahuan baik, yaitu sebanyak 103 orang $(50 \%)$, berpengetahuan cukup sebanyak 64 orang $(31,1 \%)$ dan berpengetahuan kurang sebanyak 39 orang $(18,9 \%)$. Pada kategori pengetahuan tentang jenis dismenorea, dapat dilihat bahwa siswi berpengetahuan baik sebanyak 123 orang $(59,7 \%)$, berpengetahuan cukup 32 orang $(15,5 \%)$, dan berpengetahuan kurang sebanyak 51 orang $(24,8 \%)$.

Berbeda dengan kategori sebelumnya, pada kategori penyebab dismenorea siswi berpengetahuan baik cenderung sedikit yaitu hanya 30 orang $(14,6 \%)$, berpengetahuan cukup sebanyak 60 orang $(29,1 \%)$ dan berpengetahuan kurang memiliki prosentase tertinggi yaitu 116 orang (56,3\%). Pada kategori pengetahuan tentang faktor resiko dismenorea, dapat dilihat bahwa siswi berpengetahuan baik sebanyak 143 orang $(69,4 \%)$, berpengetahuan cukup 32 orang $(15,5 \%)$ dan berpengetahuan kurang sebanyak 31 orang $(15 \%)$.

Pada kategori pengetahuan tentang derajat nyeri haid, dapat dilihat bahwa siswi berpengetahuan baik sebanyak 104 orang $(50,5 \%)$, berpengetahuan cukup 40 orang $(19,4 \%)$, dan berpengetahuan kurang sebanyak 62 orang $(30,1 \%)$. Pada kategori pengetahuan tentang tata laksana dismenorea, dapat dilihat bahwa siswi berpengetahuan baik sebanyak 134 orang (65\%), 
berpengetahuan cukup 31 orang (15\%), dan berpengetahuan kurang sebanyak 41 orang $(19,9 \%)$.

\section{PEMBAHASAN}

Berdasarkan tabel 3, dapat dilihat bahwa pengetahuan siswi tentang pengertian dismenorea menunjukan pengetahuan baik, yaitu sebanyak 103 orang (50\%), berpengetahuan cukup sebanyak 64 orang $(31,1 \%)$ dan berpengetahuan kurang sebanyak 39 orang $(18,9 \%)$. Pada kategori pengetahuan tentang jenis dismenorea, dapat dilihat bahwa siswi berpengetahuan baik sebanyak 123 orang $(59,7 \%)$, berpengetahuan cukup 32 orang $(15,5 \%)$, dan berpengetahuan kurang sebanyak 51 orang $(24,8 \%)$.

Berbeda dengan kategori sebelumnya, pada kategori penyebab dismenorea siswi berpengetahuan baik cenderung sedikit yaitu hanya 30 orang $(14,6 \%)$, berpengetahuan cukup sebanyak 60 orang $(29,1 \%)$ dan berpengetahuan kurang memiliki prosentase tertinggi yaitu 116 orang (56,3\%). Pada kategori pengetahuan tentang faktor resiko dismenorea, dapat dilihat bahwa siswi berpengetahuan baik sebanyak 143 orang (69,4\%), berpengetahuan cukup 32 orang $(15,5 \%)$ dan berpengetahuan kurang sebanyak 31 orang $(15 \%)$.

Pada kategori pengetahuan tentang derajat nyeri haid, dapat dilihat bahwa siswi berpengetahuan baik sebanyak 104 orang $(50,5 \%)$, berpengetahuan cukup 40 orang $(19,4 \%)$, dan berpengetahuan kurang sebanyak 62 orang $(30,1 \%)$. Pada kategori pengetahuan tentang tata laksana dismenorea, dapat dilihat bahwa siswi berpengetahuan baik sebanyak 134 orang (65\%), berpengetahuan cukup 31 orang (15\%), dan berpengetahuan kurang sebanyak 41 orang $(19,9 \%)$.

Pada tabel 1 didapatkan hasil karakteristik usia responden berada pada rentang 13 - 15 tahun dimana rentang usia ini di klasifikasikan sebagai usia remaja madya. Pada rentang usia ini remaja putri sudah mengalami menarche. Menarche adalah haid pertama yang terjadi akibat proses sistem hormonal yang komplek. Menarche terjadi pada usia 10 - 11 tahun (Manuaba, 2007 dalam Khamzah, 2015), dan dysmenorrhea Primer atau nyeri haid biasanya terjadi $1-2$ tahun setelah Menarche (Progestian, 2010).

Berdasarkan tabel 2 hasil penelitian menunjukkan sebagian besar responden berada pada kategori berpengetahuan baik yaitu sebanyak 115 orang dengan prosentase $55,8 \%$, sebagian kecil berpengetahuan cukup yaitu sebanyak 22 orang dengan prosentase $10,7 \%$ dan hampir setengahnya berpengetahuan kurang yaitu sebanyak 69 orang (33,5\%). Berdasarkan tabel 3, didapatkan hasil pada indikator pengertian setengahnya dikategorikan berpengetahuan baik yaitu sebanyak 103 siswi dengan persentase $50 \%$ dan hampir setengahnya berpengetahuan cukup yaitu sebanyak 64 siswi dengan prosentase $31,1 \%$. Pada indikator jenis sebagian besar termasuk dalam kategori berpengetahuan baik yaitu sebanyak 123 siswi dengan persentase 59,7\%, akan tetapi hampir setengahnya berpengetahuan kurang yaitu sebanyak 51 siswi dengan prosentase 24,8\%. Pada indikator Faktor resiko sebagian besar dikategorikan berpengetahuan baik yaitu sebanyak 143 siswi dengan persentase 69,4 dan sebagian kecil berpengetahuan cukup yaitu sebanyak 32 siswi dengan prosentase 15,5\%. Pada indikator derajat nyeri juga sebagian besar berada pada kategori berpengetahuan baik yaitu sebanyak 104 siswi dengan persentase $50,5 \%$, tetapi berpengetahuan kurang tak kalah banyak dengan hasil hampir setengahnya berpengetahuan kurang yaitu sebanyak 62 siswi dengan prosentase $30,1 \%$. Pada indikator tata laksana dismenorea pun sebagian besar dikategorikan berpengetahuan baik yaitu sebanyak 134 siswi dengan persentase $65 \%$.

Baiknya hasil pada setiap indikator bisa saja dikarenakan siswa dan siswi dipermudah dengan adanya media informasi berteknologi 
tinggi, sehingga jika keluhan nyeri haid timbul bisa mencari cara penanganannya di internet. Hal ini sejalan dengan Erfandi (2009), semakin majunya teknologi akan tersedia bermacam -macam media massa yang dapat mempengaruhi pengetahuan masyarakat tentang inovasi baru. Berbagai bentuk media komunikasi seperti televisi, radio, surat kabar, majalah dan lain - lain mempunyai pengaruh besar terhadap pembentukan opini dan kepercayaan orang.

Hasil penelitian ini sejalan dengan penelitian sebelumnya yaitu Ulayah (2012) dengan judul " Gambaran Tingkat Pengetahuan Remaja Putri Kelas VIII Tentang Penanganan Dismenorea di MTS Pondok Pesantren Al -Amien Prenduan Sumenep Madura" dengan hasil penelitian menunjukan bahwa yang diperoleh sebagian besar $(58,1 \%)$ remaja putri berpengetahuan baik dan $(41,9 \%)$ berpengetahuan cukup. Hasil ini terjadi karena media informasi di tempat tersebut memadai dan ditempat tersebut setiap seminggu sekali selalu diadakan acara pendidikan kesehatan dalam jadwal keputrian yang salah satunya membahas tentang kesehatan reproduksi.

Berbeda dengan penelitian yang dilakukan oleh Inda Irmawati (2012) dengan judul " Gambaran Tingkat Pengetahuan remaja Putri Tentang Penanganan dismenorea di Wonosari Wetan RT 1 RW 7 Kelurahan Wonokusumo Surabaya" dengan hasil penelitian yang diperoleh sebagian besar responden berpengetahuan kurang $(73,3 \%)$ dan (26,67\%) berpengetahuan cukup. Perbedaan hasil dari kedua penelitian tersebut dipengaruhi oleh lokasi penelitian, dimana pada penelitian pada lokasi ini media informasi kurang terakses dan media belajar kurang memadai dan jumlah sampel yang diteliti hanya $1 \mathrm{RT}$.

\section{SIMPULAN}

Berdasarkan hasil penelitian dapat disimpulkan bahwa gambaran pengetahuan remaja madya (13 - 15 tahun) tentang
Dysmenorrhea di SMPN 29 Kota Bandung didapatkan hasil sebagian besar pengetahuan siswi berada pada kategori berpengetahuan baik dengan hasil sebanyak 115 siswi dengan persentase $55,8 \%$. Namun, masih ditemukan sebagian kecil siswi dalam kategori berpengetahuan cukup yaitu sebanyak 22 siswi dengan persentase $10,7 \%$ dan hampir setengahnya berpengetahuan kurang yaitu sebanyak 69 siswi dengan persentase $33,5 \%$.

\section{DAFTAR PUSTAKA}

Alwi, Hasan. (2011) . Kamus Besar Bahasa Indonesia. Jakarta: Balai Pustaka.

Arikunto, Suharsimi. (2013). Prosedur Penelitian Suatu Pendekatan Praktik. Jakarta: Rineka Cipta.

Astarto. (2011). Kupas Tuntas Kelainan Haid. Bandung : Departemen Obstetri dan Ginekologi UNPAD..

Cakir, Murat. (2007). Menstrual Pattern and Common Menstrual Disorder among University Student in Turkey. Pediatrics Internasional, 49, 938 -942.

Erfandi. (2009). Pengetahuan dan faktorfaktor yang mempengaruhi. [Internet]

http://forbetterhealth.wordperss.

Hudson, Tori. (2007). Using Nutrition to Relieve Primary Dysmenorrhea. Alternative \& Complementary Therapies. Marry Ann Liebert, Inc , 125 - 128.

Irmawati, I. (2012). Gambaran Tingkat Pengetahuan Remaja Putri Tentang Penanganan Dismenorea di Wonosari Kelurahan Wonokusumo Surabaya. STIKES YARSIS Surabaya.

Kusmiran, Eny. (2011). Kesehatan reproduksi remaja dan wanita. Jakarta : Salemba Medika.

Masunah, Juju . (2011). Profil Pendidikan Kesehatan dan Sosial Remaja Kota Bandung. Lppm.upi.edu di akses tgl 06 maret 2016.

Notoatmodjo, S. (2010). Metodologi Penelitian Kesehatan. Jakarta: Rineka Cipta. 
Progestian, P. (2010). Cara Menentukan Masa Subur. Jakarta : Swarna Bumi.

Proverawati, M. (2009). Menarche, Menstruasi Penuh Makna.Yogyakarta : Nuha Medika.

Releghea, A.Y. (2012). Hubungan Antara Pengetahuan tentang Dismenore dengan Perilaku Penanganan Dalam Mengatasinya Pada Remaja Putri di RSBI SMAN Mojoagung. Diakses tanggal 10 maret 2016.

Ulayah. (2012). Gambaran Tingkat Pengetahuan Remaja Putri Kelas VIII Tentang Penanganan Dismenorea di
MTS Pondok Pesantren Al - Amien Prenduep Sumenep Madura. STIKES YARSIS Surabaya.

Yu Ting Chang \& Yueh Chih Chen. (2009). Study of Menstrual Attitudes and Distress Among Postmenarcheal Female Students in Hualien Country. Journal of Nursing Research, 17(1), 20 - 28.

Zukri, Shamsunawie Mohd, et al., (2009). Primary Dysmenorrhea among medical and Dental. University Students in Kelantan: Prevalence and Associated Factors. International Medical Journal, $16(2), 93-99$. 